\section{Anaphylaxie auf koschere Marshmallows}

0 Minuten nach dem Verzehr von gegrilltem Rindfleisch und Marshmallows entwickelte ein zwölfjähriger Junge eine massive anaphylaktische Reaktion. Nach einer stationären Behandlung erholte er sich rasch. Bei ihm war eine Allergie gegen Fisch bekannt. Bei dem Barbecue wurden jedoch keinerlei Fischgerichte angeboten. Den entscheidenden Hinweis gab die Überprüfung der Marshmallows: In ihnen war als (koscherer) Zusatz Gelatine nicht vom Schwein, sondern aus Fisch enthalten. Bei dem Patienten war sowohl spezifisches Serum-IgE als auch ein positiver Hauttest gegen

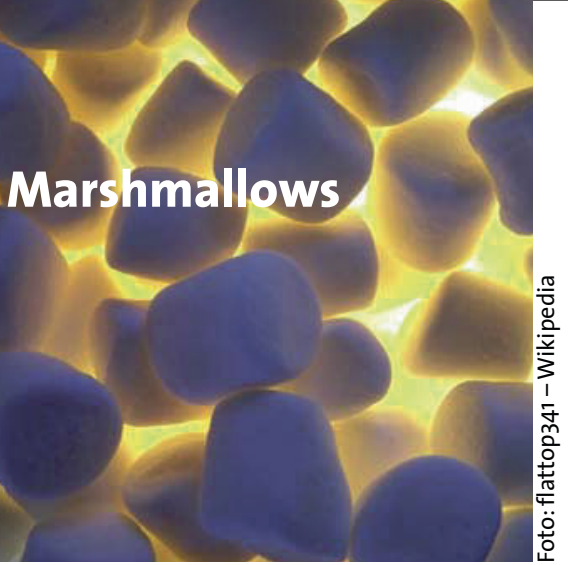

Fischgelatinezubereitungen nachweisbar, weiter auch gegen Präparationen aus Fischgelatine-haltigen Marshmallows. af

Kuehn A et al. J Allergy Immunol 2009; 123: 708-9

\title{
Fischöl gegen ASS-Intoleranz
}

$P$ atienten mit einer Intoleranz gegenüber Acetylsalicylsäure (ASS) produzieren - vermutlich aufgrund eines genetischen Polymorphismus von LeukotrienSyntheseenzymen - nach einer Cyclooxygenasehemmung durch ASS vermehrt inflammatorische Cysteinylleukotriene wie LTC4 und LTD4. Durch Zufuhr von mehrfach ungesättigten Omega-3-Fettsäuren (PUFA) wird die Synthese von Vorläufern der Cysteinylleukotriene wie Arachidonsäure gehemmt. Dass hochdosierte PUFA tatsächlich die Symptome einer ASS-Intoleranz lindern, zeigen die Fälle von drei Betroffenen, die an schwerer
Urtikaria und Asthma litten und systemische Glukokortikoide benötigten. Nach Einnahme von täglich $10 \mathrm{~g}$ PUFA-reichem Fischöl über sechs bis acht Wochen verschwanden die Symptome, die Glukokortikoide konnten abgesetzt werden. Zwei Patienten mit chronischer idiopathischer Urtikaria und Angioödemen ohne ASSIntoleranz sprachen dagegen nicht auf PUFA an, was die These eines Cysteinylleukotrien-antagonistischen Effekts der Omega-3-Fettsäuren unterstützt. $\quad b k$

Healy E et al. Br J Dermatol 2008; 159: 1368-9

\section{Inhalator als Spielzeug}

A sthma-Inhalationsgeräte verleiten Kinder offenbar auch zum Spielen und Experimentieren, wie der folgende Fall aus England zeigt: Ein 13-jähiger Junge hatte die Düse des Inhalationsgeräts seiner asthmakranken Schwester direkt auf seinen Handrücken gesetzt und einige Hübe auf die Haut puffen lassen. Einige Tage später entstanden an der Stelle Blasen. Auf Befragen gab der Junge zu, dass nicht nur die Blasen von den Inhalator-Spielereien stammten. Ein rötlicher Fleck etwa an der selben Stelle erinnerte an ein vergleichbares Experiment vor einem Jahr. Auslöser der Läsionen dürften Verätzungen durch die hochkonzentrierten Inhalationssubstanzen bzw. durch das Treibmittel sein. Auch Kälteschäden oder Abschürfungen kommen als Ursache in Frage.

$b k$

Arun B et al. Br J Dermatol 2009; 160: 197

\section{Neues Hundeallergen}

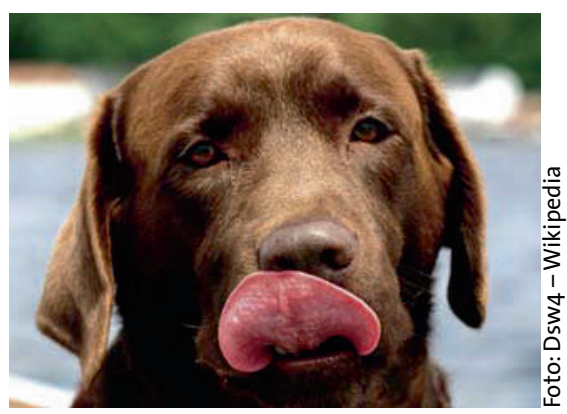

\section{Hör- und Sehverlust durch die Hüfte?}

\begin{abstract}
들 58-jährige Frau klagte über eine zunehmende Verschlechterung ihres Hörund Sehvermögens. Die Neurologen stellten die Verdachtsdiagnose einer möglicherweise immunvermittelten Polyneuropathie, eine Therapie mit Glukokortikoiden zeigte jedoch kaum Wirkung. Bei der toxikologischen Untersuchung fanden sich hohe Konzentrationen von Kobalt und Chrom in Urin, Plasma und Liquor. Vor einem Jahr war bei einer Hüft-
\end{abstract}

operation die Revision einer Endoprothese vorgenommen worden. Nachdem Ionenchelatoren keinen Erfolg brachten, wurde die Prothese ersetzt. Im Gewebe waren dabei hohe Konzentrationen der beiden Metalle messbar. Nach der Operation kam es zu einer ständigen Verbesserung der Symptome, ein I Visusverlust blieb jedoch bestehen.

Rizzetti MC et al. Lancet 2009; 373: 1052
D ie Antigene Can f 1, Can $\mathrm{f} 2$ und Can $\mathrm{f} 3$ erklären nicht vollständig die IgE-Bindungsaktivität von Hundeepithelextrakten. Aus dem Urin von Hunden wurde nun Prostata-Kallikrein als ein weiteres Majorallergen identifiziert. Ein in Hefepilzen rekombinant erzeugtes identisches Protein zeigte eine IgE-Bindung bei 26 von 37 Patienten (70\%) mit Hundeallergien, von denen 14 nicht mit den drei anderen Majorallergenen reagierten. Es besteht eine Kreuzreaktion mit dem humanen Prostata-spezifischen Antigen.

Mattsson L et al. J Allergy Clin Immunol 2009; 123:362-8 